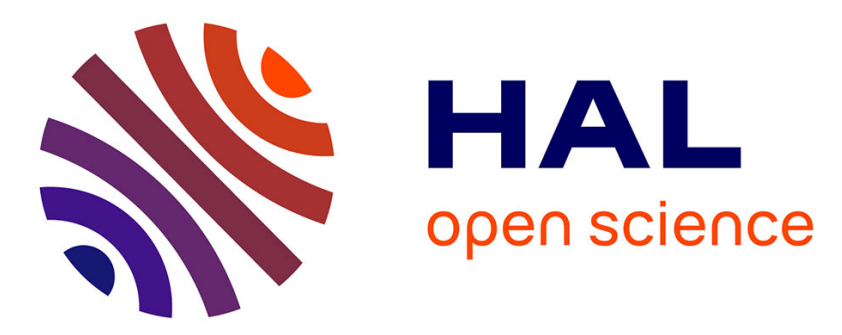

\title{
Neutron spectroscopy on protein solutions employing backscattering with an increased energy range
}

Christian Beck, Markus Appel, Marco Grimaldo, Felix Roosen-Runge, Fajun Zhang, Bernhard Frick, Frank Schreiber, Tilo Seydel

\section{- To cite this version:}

Christian Beck, Markus Appel, Marco Grimaldo, Felix Roosen-Runge, Fajun Zhang, et al.. Neutron spectroscopy on protein solutions employing backscattering with an increased energy range. Physica B: Condensed Matter, 2019, 562, pp.31-35. 10.1016/j.physb.2018.11.058 . hal-02896073

\section{HAL Id: hal-02896073 https://hal.science/hal-02896073}

Submitted on 10 Jul 2020

HAL is a multi-disciplinary open access archive for the deposit and dissemination of scientific research documents, whether they are published or not. The documents may come from teaching and research institutions in France or abroad, or from public or private research centers.
L'archive ouverte pluridisciplinaire HAL, est destinée au dépôt et à la diffusion de documents scientifiques de niveau recherche, publiés ou non, émanant des établissements d'enseignement et de recherche français ou étrangers, des laboratoires publics ou privés.

$$
\text { Copyright }
$$




\title{
Neutron spectroscopy on protein solutions employing backscattering with an increased energy range
}

\author{
Christian Beck ${ }^{\mathrm{a}, \mathrm{b}}$, Markus Appel ${ }^{\mathrm{a}, \mathrm{c}}$, Marco Grimaldo ${ }^{\mathrm{a}}$, Felix \\ Roosen-Runge $^{\mathrm{d}}$, Fajun Zhang ${ }^{\mathrm{b}}$, Bernhard Frick ${ }^{\mathrm{a}}$, Frank Schreiber $^{\mathrm{b}}$, Tilo \\ Seydel ${ }^{\mathrm{a}, *}$ \\ ${ }^{a}$ Institut Max von Laue - Paul Langevin (ILL), 71 Avenue des Martyrs, CS20156, \\ F-38042 Grenoble, France \\ ${ }^{b}$ Institut für Angewandte Physik, Eberhard-Karls-Universität Tübingen, Auf der \\ Morgenstelle 10, D-72076 Tübingen, Germany \\ ${ }^{c}$ Center for Medical Physics and Technology, Friedrich-Alexander Universität \\ Erlangen-Nürnberg, Henkestrasse 91, D-91052, Erlangen, Germany \\ ${ }^{d}$ Physical Chemistry - Kemicentrum, Lund University, PO Box 124, SE-221 00 Lund, \\ Sweden
}

\begin{abstract}
Novel cold neutron backscattering spectrometers contribute substantially to the understanding of the diffusive dynamics of proteins in dense aqueous suspensions. Such suspensions are fundamentally interesting for instance in terms of the so-called macromolecular crowding, protein cluster formation, gelation, and self-assembly. Notably, backscattering spectrometers with the highest flux can simultaneously access the center-of-mass diffusion of the proteins and the superimposed internal molecular diffusive motions. The nearly complete absence of protein-protein collisions on the accessible nanosecond observation time scale even in dense protein suspensions implies that neutron backscattering accesses the so-called short-time limit for the center-of-mass diffusion. This limit is particularly interesting in terms of a theoretical un-
\end{abstract}

\footnotetext{
${ }^{*}$ Corresponding author, e-mail: seydel@ill.eu, phone ++33476 207579
} 
derstanding by concepts from colloid physics. Here we briefly review recent progress in studying protein dynamics achieved with the latest generation of backscattering spectrometers. We illustrate this progress by the first data from a protein solution using the backscattering-and-time-of-flight option BATS on IN16B at the ILL and we outline future perspectives.

Keywords: cold neutron backscattering, aqueous protein solutions, self-diffusion

\section{Introduction}

Proteins in aqueous liquid suspensions are subject to a superposition of their center-of-mass diffusion and their internal diffusive molecular motions. These diffusive motions on the nanometer length scale can generally be well accessed by neutron backscattering spectrometers $[1,2,3,4,5]$. When such a backscattering experiment probes protonated tracer proteins dissolved in heavy water $\left(\mathrm{D}_{2} \mathrm{O}\right)$, the recorded signal from the incoherent scattering of the proteins informs on their self-diffusive dynamics. The complexity of this hierarchically superimposed center-of-mass and internal dynamics in dense aqueous protein solutions has been subject to numerous studies using neutron spectroscopy $[2,4,5,6,7,8,9,10,11,12,13,14,15,16,17,18]$. On the nanosecond time scale observed in a backscattering experiment, the measured protein center-of-mass diffusion corresponds to the colloidal short-time limit, on which protein-protein collisions are negligible and hydrodynamic interactions are dominant [19], providing one of the aspects of the useful complementarity of quasi-elastic neutron spectroscopy (QENS) to nuclear magnetic resonance (NMR) measurements on protein solutions [19, 20]. The center-of- 
mass diffusion is represented by an observable apparent diffusion coefficient $D$ which is an implicit function $D=D\left(D_{t}, D_{r}\right)$ of the translational $D_{t}$ and rotational $D_{r}$ diffusion coefficients $[19,21]$. In the short-time limit, colloid physics models describing the diffusion of hard spheres [22] can be applied to quantitatively understand the dependence of $D_{t}=D_{t}(\varphi)$ and $D_{r}=D_{r}(\varphi)$ on the volume fraction $\varphi$ occupied by the proteins in the sample solution [19]. Neutron backscattering experiments have already explored protein solutions in a wide range of protein concentrations from below $50 \mathrm{mg} / \mathrm{ml}$ up to above $500 \mathrm{mg} / \mathrm{ml}[12,19]$. Current topics of interest include for instance the investigation of protein cluster formation $[11,15,17,23,24,25,26,27,28]$, the dynamics of intrinsically disordered proteins $[8,29,30,31,32]$, the effect of crowding under pressure [33, 34], and thermal unfolding $[4,5,35,36,37]$. Moreover, the effect of ion-induced charges in protein solutions has moved into the focus of current research, driven by a mutual inspiration of experiments on the phase behavior of protein solutions tuned by the presence of multivalent salts $[11,38,39]$ and the theory of so-called patchy colloids (Refs. [40, 41] and references therein).

The quasi-elastic scattering signal $S(q, \omega)$ from a protein solution depending on the energy transfer $\omega$ and magnitude of the scattering vector $q$ can be modeled by [42]

$$
\begin{aligned}
S(q, \omega)= & \mathcal{R}(q, \omega) \otimes\left\{\beta ( q ) \left[A_{0}(q) \mathcal{L}(\gamma(q), \omega)+\right.\right. \\
& \left.\left(1-A_{0}(q)\right) \mathcal{L}(\Gamma(q)+\gamma(q), \omega)\right] \\
& \left.+\beta_{\mathrm{D}_{2} \mathrm{O}}(q) \mathcal{L}\left(\gamma_{\mathrm{D}_{2} \mathrm{O}}(q), \omega\right)\right\}
\end{aligned}
$$

where $\mathcal{R}$ is the spectrometer resolution function, $\beta, \beta_{\mathrm{D}_{2} \mathrm{O}}$ and $A_{0}$ are scalars, 
and $\mathcal{L}$ Lorentzian functions. The symbol $\otimes$ represents the convolution. The Lorentzian widths $\gamma, \Gamma$, and $\gamma_{\mathrm{D}_{2} \mathrm{O}}$ are associated with the center-of-mass and internal diffusion of the proteins and with the $\mathrm{D}_{2} \mathrm{O}$ solvent contribution, respectively. $A_{0}(q)$ is the Elastic Incoherent Structure Factor (EISF). $\mathcal{L}(\Gamma(q)+\gamma(q), \omega)$ may be replaced by a more general function such as a generalized model of internal diffusivity [5, 43], the Fourier transform of a Kohlrausch [4, 16, 44, 45] or Mittag-Leffler [46, 47, 48] function, or the result of a molecular dynamics simulation, if applicable. In reported backscattering experiments on protein solutions, the apparent center-of-mass diffusion was consistent with simple Brownian diffusion, $\gamma(q)=D q^{2}[9,15,17,19]$.

To best measure $S(q, \omega)$ (equation 1), a good energy resolution to best capture $\gamma(q)$ as well as sufficient ranges in $q$ and $\omega$ to access $A_{0}(q)$ and $\Gamma(q)$ are required, as discussed in the following section.

\section{Progress in backscattering instrumentation}

Cold neutron backscattering spectrometers outfitted with Silicon(111) analyzer crystals associated with the elastic wavelength $\lambda \approx 6.27 \AA$ are ideally suited to observe the short-time center-of-mass self-diffusion and the superimposed internal diffusion. For a good comparison of the experimental EISF to models, a high maximum $q$ of nearly $2 \AA^{-1}$ as obtained with $\operatorname{Si}(111)$ analyzer crystals is very useful. An energy resolution on the order of $1 \mu \mathrm{eV}$ is required to measure the center-of-mass diffusion. To also access the internal dynamics, a sufficient energy range is additionally needed. Finally, the possibility to simultaneously measure both the center-of-mass diffusion of proteins in rather dilute aqueous solutions and the internal molecular mo- 
tions of these proteins requires the high flux and good signal-to-noise ratios of the most recent backscattering spectrometers [49, 50, 51, 52, 53, 54]. These spectrometers are located at the brightest cold neutron sources $[55,56]$ and are based on advances in neutron optics such as the phase space transformation in the case of exact backscattering [57] and modern neutron guide layouts [58].

So far, backscattering spectrometers have followed two complementary design concepts: (1) the concept of exact backscattering, where both the monochromator and analyzer single crystal reciprocal lattice vectors are oriented precisely parallel to the neutron optical axis and, thus, achieving the best energy resolution. These instruments are typically located at neutron sources that are continuous in time $[50,53,59,60]$. The excellent energy resolution in this design comes at the cost of a limited maximum energy transfer range given by the requirement that this transfer can with the current stateof-the-art only be reasonably achieved by carrying out the monochromatizing Bragg reflection in a mechanically moving reference frame. (2) The alternative design concept obtains the wavelength definition of the incident beam at the sample position by the spread with flight time of an initially very brief but polychromatic neutron pulse $[50,51,61,62,63]$. This design increases the energy range and comes at the expense of a lower energy resolution compared to concept (1).

The spectrometer IN16B [50,64] combined with its optional configuration denoted BATS (Backscattering-And-Time-of-flight Spectrometer) [52, 65] for the first time aims at providing both these concepts in one single instrument, where the BATS option represents concept (2). BATS notably provides the 
possibility to tune the energy range and resolution within certain ranges by changing the chopper settings [65]. For more detailed information we refer to Refs. $[52,65]$ and the dedicated article on BATS within this proceedings volume [66]. In the following section we report on the first application of the BATS option to record a QENS spectrum on a protein solution sample.

\section{First QENS signal from a protein solution using BATS}

During the first ILL reactor cycle with IN16B operating in the BATS configuration (March/April 2018), we have recorded QENS data on a solution of bovine serum albumin (BSA) proteins dissolved in heavy water $\left(\mathrm{D}_{2} \mathrm{O}\right)$. The sample was prepared by dissolving $m_{p}=300 \mathrm{mg}$ of BSA powder as purchased from Sigma-Aldrich (catalog number A3059, batch number SLBR6762V) without further purification in $V=1.5 \mathrm{~mL} \mathrm{D}_{2} \mathrm{O}$, such that the dry protein volume fraction in the sample solution amounted to $\varphi=m_{p} v_{p} /\left(V+m_{p} v_{p}\right) \approx$ 0.13 with the specific volume of BSA $v_{p}=0.735 \mathrm{~mL} / \mathrm{g}[17,19]$. We remark that for a conclusive interpretation of crowding effects on protein diffusion, an effective hydrodynamic volume fraction taking into account effects of nonsphericity and hydration has to be used, as explained in Ref. [19]. Part of the prepared sample solution was filled in a cylindrical Al sample holder with $7 \mathrm{~mm}$ outer diameter and $0.2 \mathrm{~mm}$ difference between the inner and outer cylinder walls. Pure $\mathrm{D}_{2} \mathrm{O}$ reference data and empty can data were recorded using equivalent sample holders. The QENS data were measured at the temperature $T=295 \mathrm{~K}$ thermostated by a cryofurnace. The energy resolution was measured with a cylindrical Vanadium foil with the slightly smaller diameter of $\approx 6 \mathrm{~mm}$ than the sample cell, thus resulting in a slightly 

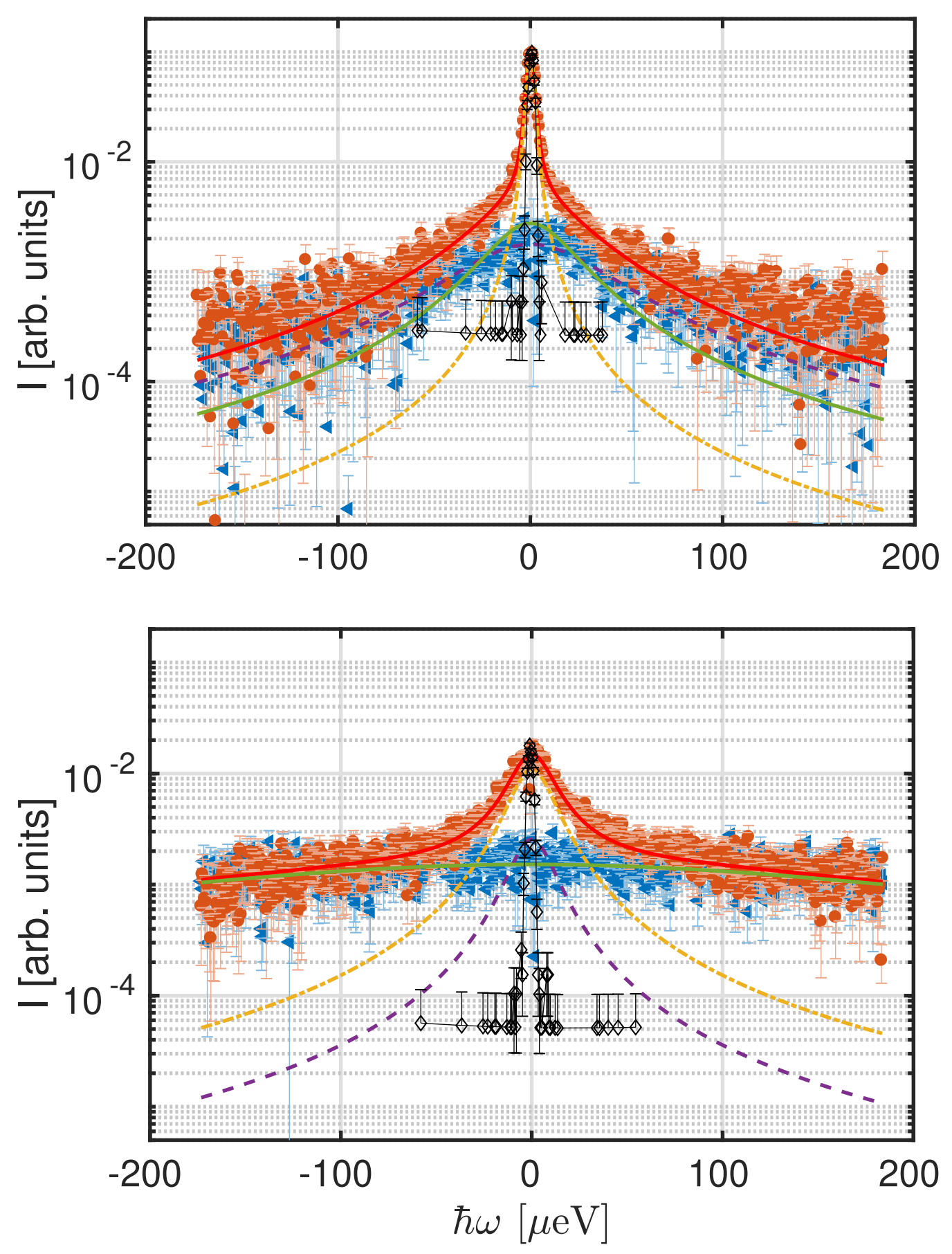

Figure 1: First spectrum (circle symbols) from a BSA protein solution in $\mathrm{D}_{2} \mathrm{O}$ recorded using the new BATS option of IN16B in a single tube of the position-sensitive detector (PSD); top: PSD tube number $1, q=0.44 \AA^{-1}$; bottom: PSD tube $14, q=1.79 \AA^{-1}$. The square symbols denote the corresponding pure $\mathrm{D}_{2} \mathrm{O}$ solvent reference spectrum. The red solid line superimposed on the $\mathrm{BSA} / \mathrm{D}_{2} \mathrm{O}$ spectrum denotes the fit of equation 1 consisting of the Lorentzian contributions with the widths $\gamma, \Gamma$, and $\gamma_{D_{2} \mathrm{O}}$, respectively, assigned to the global diffusion (dashed line), internal diffusion (dash-dotted line) and water contribution (solid line superimposed on the $\mathrm{D}_{2} \mathrm{O}$ spectrum). The diamond symbols represent the resolution function measured using Vanadium. 


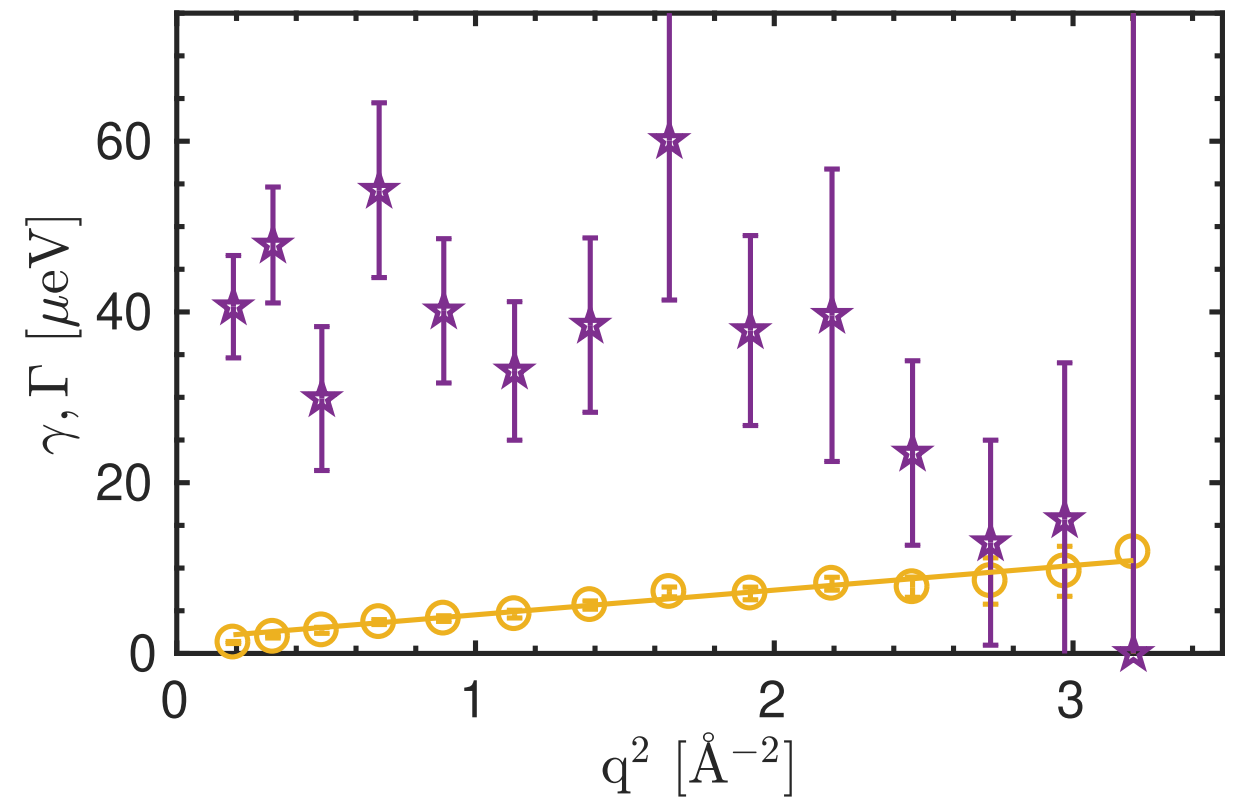

Figure 2: Fit result for the Lorenztian widths $\gamma$ (circle symbols) and $\Gamma$ (star symbols) associated with the global and internal diffusive motions of the proteins, respectively, to the spectrum recorded on BSA in $\mathrm{D}_{2} \mathrm{O}$ (figure 1) according to equation 1 . The line superimposed on the circles is a fit of an affine function $\gamma=D q^{2}+$ const. (see text). 
better resolution than actually achieved on the sample itself. The resolution linewidth was found to be $(3.1 \pm 0.2) \mu \mathrm{eV}$ Gaussian FWHM when fitting Vanadium spectra recorded in individual detectors. When summing the Vanadium spectra of all detectors, the thus obtained integrated resolution amounted to $\approx 3.3 \mu \mathrm{eV}$ FWHM.

BATS was used in the "low repetition rate configuration" [65] with the first counter-rotating chopper-pair using the $20.5^{\circ}$ slits and spinning at $79 \mathrm{~Hz}$, i.e. serving as suppressor choppers, and the second pair set to $8^{\circ}$ slits and $315 \mathrm{~Hz}$, i.e. serving as the resolution-defining choppers. It is emphasized that during the reported test experiment the specific neutron optics for BATS, namely focus optics at the choppers and before the sample, was not yet installed. Therefore, the flux at the sample was substantially below the expected final flux. The neutrons were detected by a vertically positionsensitive detector (PSD) consisting of 16 vertical tubes used to obtain 16 discrete $q$-values in the horizontal scattering plane.

The thus obtained first spectrum from a protein solution is depicted in figure 1 (circle symbols) for two $q$-values, along with the corresponding pure $\mathrm{D}_{2} \mathrm{O}$ signal (square symbols) and fit result using equation 1 (lines). The counting time for the BSA and the $\mathrm{D}_{2} \mathrm{O}$ spectrum amounted to $\approx 6.5$ hours each. The empty can contribution has been subtracted from the BSA/ $\mathrm{D}_{2} \mathrm{O}$ and pure $\mathrm{D}_{2} \mathrm{O}$ signals. The Vanadium spectrum (diamond symbols in figure 1) was measured without a can. The figure 1 illustrates the measured range in energy transfer of $-180 \mu \mathrm{eV} \leq \omega \leq+180 \mu \mathrm{eV}$, the good visibility of the solvent $\mathrm{D}_{2} \mathrm{O}$ contribution on this range, and the convergence of the protein solution and solvent reference spectra for large absolute values of $\omega$. 


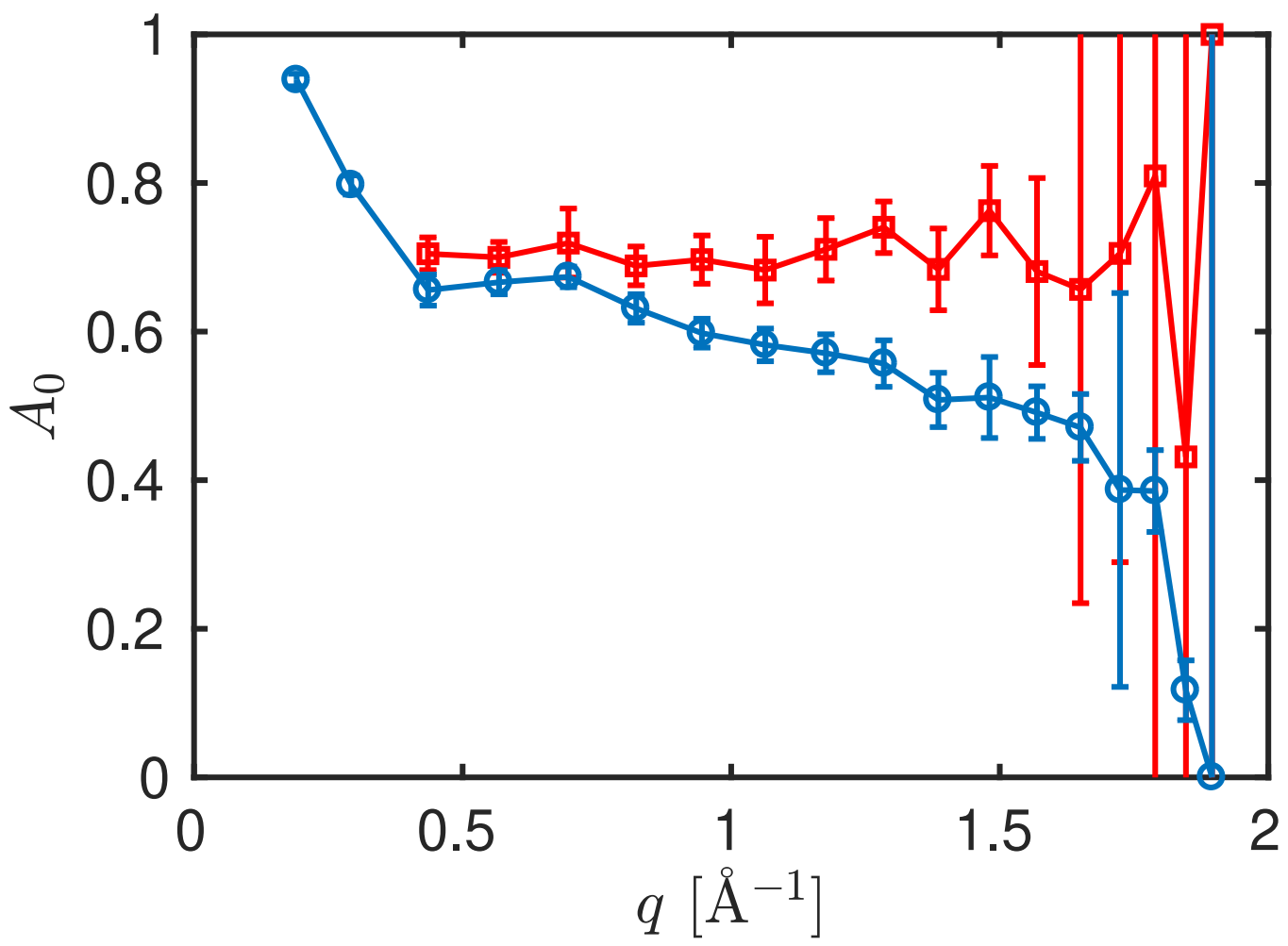

Figure 3: Elastic incoherent structure factor (EISF) $A_{0}(q)$ of BSA in $\mathrm{D}_{2} \mathrm{O}$ resulting from the fit of equation 1 to the spectra displayed in figure 1 (red square symbols). The EISF obtained from a fit of a spectrum recorded on IN16B in the exact-backscattering setup (energy resolution $\approx 0.8 \mu \mathrm{eV}$ ) is shown for reference (blue circle symbols). (Note that the detectors at the two smallest $q$-values visible in the IN16B results were not installed on BATS. The lines connecting the symbols are quides to the eye.) 
Specific IN16B/BATS software implemented in GNU Octave was used for the initial data reduction. The data analysis was carried out using software implemented in MATLAB (The MathWorks, Inc.) [42]. The fit of equation 1 (lines in figure 1) demonstrates the analysis of the first spectrum from a protein solution measured on BATS. This fit was carried out for the spectra at each $q$-value individually, i.e. without imposing any $q$-dependence in the fit. The width $\gamma_{\mathrm{D}_{2} \mathrm{O}}$ of the Lorentzian describing the water contribution was fixed using tabled values for $\mathrm{D}_{2} \mathrm{O}$ [42]. $\beta_{D_{2} O}$ was fixed using the rescaled pure solvent signal to account for the volume occupied by the proteins [42]. (Within the present accuracy, we cannot model any separate protein hydration water contribution.)

The width $\gamma(q)$ (circle symbols in figure 2) accounting for the global diffusion can be fitted by a straight line (superimposed on the circle symbols in figure 2). The slope of this line results in an apparent diffusion coefficient $D=\gamma(q) / q^{2}=(4.39 \pm 0.72) \AA^{2} /$ ns consistent with earlier IN16B results ( $D=\left(4.14 \pm 0.40 \AA^{2} / \mathrm{ns}[17]\right)$ on an equivalent sample. However, the offset $\gamma=D q^{2}+(1.6 \pm 0.6) \mu \mathrm{eV}$ of this line is not yet understood. It might arise from a partial cross-talking of contributions from the global and internal diffusion due to the broader energy resolution compared to IN16B, from an insufficient description of the internal motions by only a single Lorentzian [5], from a possibly energy-dependent background contribution, and from the resolution data measured in a slightly different geometry.

The fit result for the linewidth $\Gamma$ (square symbols in figure 2) is consistent within the errors with previous results from IN16B in the intermediate $q$-range. The expected improved signal-to-noise ratio with the full implemen- 
tation of the BATS neutron optics will substantially increase the accuracy of this information and allow for fitting more complex models. The EISF $A_{0}(q)$ (figure 3 ) is reasonably close to a previous IN16B result. In view of the broader energy resolution of BATS, it is consistently slightly above the IN16B result by sampling more motions as "static" within the resolution.

Some uncertainties remain regarding this first test spectrum on a single sample and its interpretation, since the resolution was measured with a slightly different geometry and since an old batch of BSA proteins was used. Moreover, an energy-dependent background may be present in the measured data, which was not considered in the analysis. For these reasons, the present data and analysis cannot serve as quantitative reference for future studies. Nevertheless, these first data outline the promising possibilities with the large $\omega$-range and the good energy resolution in a large $q$-range.

\section{Conclusions and outlook}

In this proceedings article we have discussed the use of cold neutron backscattering spectrometers to study the superimposed center-of-mass and internal molecular diffusivities of proteins in aqueous solutions. We have shown the first commissioning data recorded employing the new instrument option BATS at IN16B on a liquid suspension of BSA proteins in $\mathrm{D}_{2} \mathrm{O}$. These data provide a proof of concept prior to the full implementation of all neutron optics in the BATS configuration and, thus, prior to the implementation of the full design neutron flux in the BATS configuration. Moreover, these data can already be quantitatively analyzed using established frameworks, thus pointing to the future possibilities when the full flux and optimized 
signal-to-noise ratio will be achieved on BATS. By modeling our data using equation 1 , we separate the different contributions to the spectrum by the protein and by the solvent, respectively, via the associated signal intensities and linewidths, as well as by evaluating the additional pure solvent data. A polarization option may be of interest for the future to better experimentally separate the contributions.

We have highlighted the need for versatile backscattering options with complementary energy ranges and resolutions to study the dynamics of proteins in water. Notably, IN16B and its BATS option will provide a choice of different energy resolutions and ranges that would otherwise require the use of several instruments. These new backscattering options open up perspectives for a systematic study of various topics such as the crowding effect in protein solutions, the formation of static or transient protein clusters, the self-assembly of protein aggregates, the thermal unfolding and denaturing of proteins, and the effect of salt-induced charges in protein solutions. These experiments will profit from the large and well-suited range in $q$ - to access the EISF and the $q$-dependence of the diffusion processes - as well as $\omega$ - to access both the center-of-mass and internal molecular diffusion. The increased range in $\omega$ will benefit amongst other topics the experiments on more dilute protein suspensions as well as at elevated temperatures where the overall dynamics becomes too fast for the energy range covered by the exact backscattering configuration. 


\section{Acknowledgement}

BATS was funded by the German Ministry for Education and Research (BMBF Verbundforschung grants 05K13WE1 and 05K16WEA). The research on protein solutions has been supported by the DFG and the ANR. C.B. acknowledges a PhD studentship grant co-funded by the University of Tübingen and the ILL. M.G. acknowledges support by the ANR (grant ANR-16-CE920009), and F.R.-R. by the Knut and Alice Wallenberg Foundation (project grant KAW 2014.0052). B.F., M.A., and T.S. are grateful for stimulating discussions at the QENS/WINS conference in Hong Kong 2018.

\section{References}

[1] C. Caronna, F. Natali, A. Cupane, Incoherent elastic and quasielastic neutron scattering investigation of hemoglobin dynamics, Biophys. Chem. 116 (3) (2005) $219-225$.

[2] M. Jasnin, M. Moulin, M. Haertlein, G. Zaccai, M. Tehei, In Vivo Measurement of Internal and Global Macromolecular Motions in Escherichia coli, Biophys. J. 95 (2) (2008) 857 - 864. doi:10.1529/biophysj.107.124420.

[3] A. M. Stadler, L. van Eijck, F. Demmel, G. Artmann, Macromolecular Dynamics in Red Blood Cells Investigated Using Neutron Spectroscopy, J. R. Soc., Interface 8 (57) (2011) 590-600. doi:10.1098/rsif.2010.0306.

[4] M. Hennig, F. Roosen-Runge, F. Zhang, S. Zorn, M. W. A. Skoda, R. M. J. Jacobs, T. Seydel, F. Schreiber, Dynamics of Highly Concen- 
trated Protein Solutions Around the Denaturing Transition, Soft Matter 8 (2012) 1628-1633. doi:10.1039/C1SM06609A.

[5] M. Grimaldo, F. Roosen-Runge, M. Hennig, F. Zanini, F. Zhang, N. Jalarvo, M. Zamponi, F. Schreiber, T. Seydel, Hierarchical Molecular Dynamics of Bovine Serum Albumin in Concentrated Aqueous Solution Below and Above Thermal Denaturation, Phys. Chem. Chem. Phys. 17 (2015) 4645-4655. doi:10.1039/C4CP04944F.

[6] V. Réat, R. Dunn, M. Ferrand, J. L. Finney, R. M. Daniel, J. C. Smith, Solvent dependence of dynamic transitions in protein solutions, Proc. Natl. Acad. Sci. USA 97 (2000) 99619966.

[7] J. Pérez, J.-M. Zanotti, D. Durand, Evolution of the internal dynamics of two globular proteins from dry powder to solution, Biophysical Journal 77 (1) (1999) 454-469.

[8] A. M. Stadler, L. Stingaciu, A. Radulescu, O. Holderer, M. Monkenbusch, R. Biehl, D. Richter, Internal Nanosecond Dynamics in the Intrinsically Disordered Myelin Basic Protein, J. Am. Chem. Soc. 136 (19) (2014) 6987-6994, pMID: 24758710. doi:10.1021/ja502343b.

[9] M. Grimaldo, F. Roosen-Runge, F. Zhang, T. Seydel, F. Schreiber, Diffusion and Dynamics of $\gamma_{-}$Globulin in Crowded Aqueous Solutions, J. Phys. Chem. B 118 (2014) 7203-7209. doi:dx.doi.org/10.1021/jp504135z.

[10] M. Monkenbusch, A. Stadler, R. Biehl, J. Ollivier, M. Zamponi, 
D. Richter, Fast Internal Dynamics in Alcohol Dehydrogenase, J. Chem. Phys. 143 (7) (2015) 075101. doi:10.1063/1.4928512.

[11] M. Grimaldo, F. Roosen-Runge, M. Hennig, F. Zanini, F. Zhang, M. Zamponi, N. Jalarvo, F. Schreiber, T. Seydel, Salt-Induced Universal Slowing Down of the Short-Time Self-Diffusion of a Globular Protein in Aqueous Solution, J. Phys. Chem. Lett. 6 (2015) 2577-2582. doi:10.1021/acs.jpclett.5b01073.

[12] S. Fujiwara, K. Araki, T. Matsuo, H. Yagi, T. Yamada, K. Shibata, H. Mochizuki, Dynamical Behavior of Human $\alpha$-Synuclein studied by Quasielastic Neutron Scattering, PloS one 11 (4) (2016) e0151447.

[13] S. Longeville, L.-R. Stingaciu, Hemoglobin diffusion and the dynamics of oxygen capture by red blood cells, Sci. Rep. 7 (1) (2017) 10448.

[14] D. Anunciado, V. Nyugen, G. Hurst, M. Doktycz, V. Urban, P. Langan, E. Mamontov, H. ONeill, In Vivo Protein Dynamics on the Nanometer Length Scale and Nanosecond Time Scale, J. Phys. Chem. Lett. 8 (8) (2017) 1899-1904.

[15] M. K. Braun, M. Grimaldo, F. Roosen-Runge, I. Hoffmann, O. Czakkel, M. Sztucki, F. Zhang, F. Schreiber, T. Seydel, Crowding-Controlled Cluster Size in Concentrated Aqueous Protein Solutions: Structure, Selfand Collective Diffusion, J. Phys. Chem. Lett. 8 (2017) 2590-2596.

[16] F. Ameseder, A. Radulescu, M. Khaneft, W. Lohstroh, A. M. Stadler, Homogeneous and Heterogeneous Dynamics in Native and Denatured 
Bovine Serum Albumin, Phys. Chem. Chem. Phys. 20 (2018) 5128-5139. doi:10.1039/C7CP08292D.

[17] C. Beck, M. Grimaldo, F. Roosen-Runge, M. Braun, F. Zhang, F. Schreiber, T. Seydel, Nanosecond Tracer Diffusion as a Probe of the Solution Structure and Molecular Mobility of Protein Assemblies: The Case of Ovalbumin, The Journal of Physical Chemistry B 122 (35) (2018) 8343-8350. doi:10.1021/acs.jpcb.8b04349.

[18] E. Mamontov, Microscopic diffusion processes measured in living planarians, Scientific reports 8 (1) (2018) 4190.

[19] F. Roosen-Runge, M. Hennig, F. Zhang, R. M. J. Jacobs, M. Sztucki, H. Schober, T. Seydel, F. Schreiber, Protein Self-Diffusion in Crowded Solutions, Proc. Natl. Acad. Sci. U. S. A. 108 (29) (2011) 11815-11820. doi:10.1073/pnas.1107287108.

[20] M. Roos, M. Ott, M. Hofmann, S. Link, E. Rössler, J. Balbach, A. Krushelnitsky, K. Saalwächter, Coupling and Decoupling of Rotational and Translational Diffusion of Proteins under Crowding Conditions, J. Am. Chem. Soc. 138 (2016) 10365-10372.

[21] F. Roosen-Runge, M. Hennig, T. Seydel, F. Zhang, M. W. A. Skoda, S. Zorn, R. M. J. Jacobs, M. Maccarini, P. Fouquet, F. Schreiber, Protein Diffusion in Crowded Electrolyte Solutions, Biochimica et Biophysica Acta 1804 (2010) 68-75.

[22] A. J. Banchio, G. Nägele, Short-Time Transport Properties in Dense 
Suspensions: From Neutral to Charge-Stabilized Colloidal Spheres, J. Chem. Phys. 128 (10) (2008) 104903. doi:10.1063/1.2868773.

[23] F. Cardinaux, E. Zaccarelli, A. Stradner, S. Bucciarelli, B. Farago, S. U. Egelhaaf, F. Sciortino, P. Schurtenberger, Cluster-Driven Dynamical Arrest in Concentrated Lysozyme Solutions, J. Phys. Chem. B 115 (22) (2011) 7227-7237. doi:10.1021/jp112180p.

[24] E. Yearley, P. Godfrin, T. Perevozchikova, H. Zhang, P. Falus, L. Porcar, M. Nagao, J. Curtis, P. Gawande, R. Taing, et al., Observation of Small Cluster Formation in Concentrated Monoclonal Antibody Solutions and Its Implications to Solution Viscosity, Biophys. J. 106 (8) (2014) 1763 - 1770. doi:http://doi.org/10.1016/j.bpj.2014.02.036.

[25] Y. Liu, X. Wang, C. B. Ching, Toward Further Understanding of Lysozyme Crystallization: Phase Diagram, Protein-Protein Interaction, Nucleation Kinetics, and Growth Kinetics, Cryst. Growth Des. 10 (2) (2010) 548-558. doi:10.1021/cg900919w.

URL http://pubs.acs.org/doi/abs/10.1021/cg900919w

[26] M. Erlkamp, S. Grobelny, A. Faraone, C. Czeslik, R. Winter, Solvent effects on the dynamics of amyloidogenic insulin revealed by neutron spin echo spectroscopy, J. Phys. Chem. B 118 (12) (2014) 3310-3316.

[27] L. Porcar, P. Falus, W.-R. Chen, A. Faraone, E. Fratini, K. Hong, P. Baglioni, Y. Liu, Formation of the Dynamic Clusters in Concentrated Lysozyme Protein Solutions, J. Phys. Chem. Lett. 1 (1) (2010) 126-129. doi:10.1021/jz900127c. 
[28] G. Nawrocki, P.-h. Wang, I. Yu, Y. Sugita, M. Feig, Slow-Down in Diffusion in Crowded Protein Solutions Correlates with Transient Cluster Formation, J. Phys. Chem. B 121 (49) (2017) 11072-11084. doi:10.1021/acs.jpcb.7b08785.

[29] D. J. Callaway, T. Matsui, T. Weiss, L. R. Stingaciu, C. B. Stanley, W. T. Heller, Z. Bu, Controllable activation of nanoscale dynamics in a disordered protein alters binding kinetics, J. Mol. Biol. 429 (7) (2017) 987-998.

[30] S. Perticaroli, J. D. Nickels, G. Ehlers, E. Mamontov, A. P. Sokolov, Dynamics and rigidity in an intrinsically disordered protein, $\beta$-casein, The Journal of Physical Chemistry B 118 (26) (2014) 7317-7326.

[31] A. M. Gaspar, M.-S. Appavou, S. Busch, T. Unruh, W. Doster, Dynamics of Well-Folded and Natively Disordered Proteins in Solution: a Time-of-Flight Neutron Scattering Study, European Biophysics Journal 37 (5) (2008) 573-582. doi:10.1007/s00249-008-0266-3.

[32] S. Lenton, M. Grimaldo, F. Roosen-Runge, F. Schreiber, T. Nylander, R. Clegg, C. Holt, M. Härtlein, V. García-Sakai, T. Seydel, S. C. M. Teixeira, Effect of Phosphorylation on a Human-like Osteopontin Peptide, Biophysical Journal 112 (8) (2017) 1586 - 1596. doi:10.1016/j.bpj.2017.03.005.

[33] S. Al-Ayoubi, P. Schummel, M. Golub, J. Peters, R. Winter, Influence of cosolvents, self-crowding, temperature and pressure on the sub- 
nanosecond dynamics and folding stability of lysozyme, Phys. Chem. Chem. Phys.

[34] M. Golub, N. Martinez, G. Michoud, J. Ollivier, M. Jebbar, P. Oger, J. Peters, The effect of crowding on protein stability, rigidity, and high pressure sensitivity in whole cells, Langmuir 34 (35) (2018) 10419-10425.

[35] D. Russo, J. Pérez, J.-M. Zanotti, M. Desmadril, D. Durand, Dynamic transition associated with the thermal denaturation of a small beta protein, Biophys. J. 83 (5) (2002) 2792-2800.

[36] G. Gibrat, F. Assairi, Y. Blouquit, C. Craescu, M. Bellissentfunel, Biophysical study of thermal denaturation of apo-calmodulin: Dynamics of native and unfolded states, Biophys. J. 95 (11) (2008) 5247-5256.

[37] H. Jansson, J. Swenson, Dynamical changes of hemoglobin and its surrounding water during thermal denaturation as studied by quasielastic neutron scattering and temperature modulated differential scanning calorimetry, J. Chem. Phys. 128 (24) (2008) 245104.

[38] D. Soraruf, F. Roosen-Runge, M. Grimaldo, F. Zanini, R. Schweins, T. Seydel, F. Zhang, R. Roth, M. Oettel, F. Schreiber, Protein Cluster Formation in Aqueous Solution in the Presence of Multivalent Metal Ions-a Light Scattering Study, Soft Matter 10 (6) (2014) 894-902.

[39] F. Zhang, F. Roosen-Runge, A. Sauter, M. Wolf, R. M. J. Jacobs, F. Schreiber, Reentrant Condensation, Liquid-Liquid Phase Separation and Crystallization in Protein Solutions Induced by Multivalent Metal 
Ions, Pure Appl. Chem. 86 (2) (2014) 191-202. doi:10.1515/pac-20145002.

[40] F. Roosen-Runge, F. Zhang, F. Schreiber, R. Roth, Ion-activated Attractive Patches as a Mechanism for Controlled Protein Interactions, Sci. Rep. 4 (2014) 7016.

[41] J. Bleibel, M. Habiger, M. Lütje, F. Hirschmann, F. Roosen-Runge, T. Seydel, F. Zhang, F. Schreiber, M. Oettel, Two Time Scales for Self and Collective Diffusion Near the Critical Point in a Simple Patchy Model for Proteins with Floating Bonds, Soft Matter (2018) -doi:10.1039/C8SM00599K.

[42] M. Grimaldo, F. Roosen-Runge, N. Jalarvo, M. Zamponi, F. Zanini, M. Hennig, F. Zhang, F. Schreiber, T. Seydel, High-Resolution Neutron Spectroscopy on Protein Solution Samples, EPJ Web Conf. 83 (2015) 02005. doi:10.1051/epjconf/20158302005.

[43] F. Roosen-Runge, D. Bicout, J.-L. Barrat, Analytical Correlation Functions for Motion through Diffusivity Landscapes, J. Chem. Phys. 144 (20) (2016) 204109.

[44] L. Toppozini, F. Roosen-Runge, R. I. Bewley, R. M. Dalgliesh, T. Perring, T. Seydel, H. R. Glyde, V. García-Sakai, M. C. Rheinstadter, Anomalous and anisotropic nanoscale diffusion of hydration water molecules in fluid lipid membranes, Soft Matter 11 (2015) 8354-8371. doi:10.1039/C5SM01713K. 
[45] R. Kohlrausch, Theorie des elektrischen Rückstandes in der Leidner Flasche, Annalen der Physik und Chemie 91 (1854) 56-82.

[46] M. Mittag-Leffler, Sur la Fonction Nouvelle E 1/ $\alpha$ (x), CR Acad. Sci., Paris 2 (137) (1903) 554-558.

[47] G. R. Kneller, Quasielastic Neutron Scattering and Relaxation Processes in Proteins: Analytical and Simulation-Based Models, Phys. Chem. Chem. Phys. 7 (2005) 2641-2655. doi:10.1039/B502040A.

[48] I. Krasnov, T. Seydel, I. Greving, M. Blankenburg, F. Vollrath, M. Müller, Strain-dependent fractional molecular diffusion in humid spider silk fibres, Journal of The Royal Society Interface 13 (122) (2016) 20160506.

[49] B. Frick, H. Bordallo, T. Seydel, J.-F. Barthélémy, M. Thomas, D. Bazzoli, H. Schober, How IN16 can maintain a world-leading position in neutron backscattering spectrometry, Physica B: Condensed Matter 385-386 (2006) 1101 - 1103. doi:10.1016/j.physb.2006.05.378.

[50] B. Frick, E. Mamontov, L. van Eijck, T. Seydel, Recent Backscattering Instrument Developments at the ILL and SNS, Z. Phys. Chem. (Muenchen, Ger.) 224 (2010) 33-60.

[51] E. Mamontov, K. W. Herwig, A Time-of-Flight Backscattering Spectrometer at the Spallation Neutron Source, BASIS, Rev. Sci. Instrum. 82 (8) (2011) 085109. doi:10.1063/1.3626214.

[52] L. van Eijck, L. Gérard, B. Frick, T. Seydel, H. Schober, A Case Study for Using Neutron Backscattering Instruments at Reactors in Inverted 
Time-of-Flight Mode, Nucl. Instrum. Methods Phys. Res., Sect. A 672 (2012) 64-68.

[53] J. Wuttke, A. Budwig, M. Drochner, H. Kämmerling, F.-J. Kayser, H. Kleines, V. Ossovyi, L. C. Pardo, M. Prager, D. Richter, et al., SPHERES, Jülich's high-flux neutron backscattering spectrometer at FRM II, Rev. Sci. Instrum. 83 (7) (2012) 075109.

[54] M. Appel, B. Frick, Note: One order of magnitude better signal-tonoise ratio for neutron backscattering, Rev. Sci. Instrum. 88 (3) (2017) 036105. doi:10.1063/1.4978279.

[55] P. Ageron, Cold neutron sources at ILL, Nuclear Instruments and Methods in Physics Research Section A: Accelerators, Spectrometers, Detectors and Associated Equipment 284 (1) (1989) 197-199.

[56] L. Mansur, T. Gabriel, J. Haines, D. Lousteau, R\&D for the Spallation Neutron Source mercury target, Journal of Nuclear Materials 296 (1) (2001) 1 - 16, 4th Int. Workshop on Spallation Materials Technology. doi:10.1016/S0022-3115(01)00560-8.

[57] M. Hennig, B. Frick, T. Seydel, Optimum Velocity of a Phase-Space Transformer for Cold-Neutron Backscattering Spectroscopy, J. Appl. Crystallogr. 44 (3) (2011) 467-472. doi:10.1107/S0021889811013227.

[58] H. Bordallo, B. Frick, H. Schober, T. Seydel, Primary spectrometer neutron optics simulations for a new cold neutron backscattering spectrometer, Journal of Neutron Research 16 (1-2) (2008) 39-54. 
[59] A. Meyer, R. M. Dimeo, P. M. Gehring, D. A. Neumann, The highflux backscattering spectrometer at the NIST Center for Neutron Research, Review of Scientific Instruments 74 (5) (2003) 2759-2777. doi:10.1063/1.1568557.

[60] N. de Souza, A. Klapproth, G. Iles, EMU: High-Resolution Backscattering Spectrometer at ANSTO, Neutron News 27 (2) (2016) 20-21. doi:10.1080/10448632.2016.1163985.

[61] C. Carlile, M. A. Adams, The design of the IRIS inelastic neutron spectrometer and improvements to its analysers, Physica B Condensed Matter 182 (1992) 431-440.

[62] K. Shibata, N. Takahashi, Y. Kawakita, M. Matsuura, T. Yamada, T. Tominaga, W. Kambara, M. Kobayashi, Y. Inamura, T. Nakatani, K. Nakajima, M. Arai, The Performance of TOF near Backscattering Spectrometer DNA in MLF, J-PARC, JPS Conf.Proc. 8 (2015) 036022. doi:10.7566/JPSCP.8.036022.

[63] N. Tsapatsaris, R. Lechner, M. Markó, H. Bordallo, Conceptual design of the time-of-flight backscattering spectrometer, MIRACLES, at the European Spallation Source, Rev. Sci. Instrum. 87 (8) (2016) 085118.

[64] B. Frick, M. Appel, T. Seydel, L. van Eijck, D. Bazzoli, The new backscattering spectrometer IN16B at the ILL, unpublished.

[65] M. Appel, B. Frick, A. Magerl, A Flexible High Speed Pulse Chopper System for an Inverted Neutron Time-of-Flight Option on Backscattering Spectrometers, Scientific Reports 8 (2018) 13580. 
[66] M. Appel, B. Frick, A. Magerl, First results with the neutron backscattering and tof spectrometer option bats on in $16 \mathrm{~b}$, in this conference proceedings issue. 